\title{
Black residents navigate an unequal food landscape in Washington, D.C.
}

Review by Renee Brooks Catacalos, Sustainable Agriculture and Food Systems Funders*

Review of Black Food Geographies: Race, Self-Reliance, and Food Access in Washington, D.C., by Ashanté M. Reese. (2019). Chapel Hill: University of North Carolina Press. Available as hardcover, paperback, and ebook; 184 pages. Publisher's website: https://www.uncpress.org/book/9781469651507/black-foodgeographies/

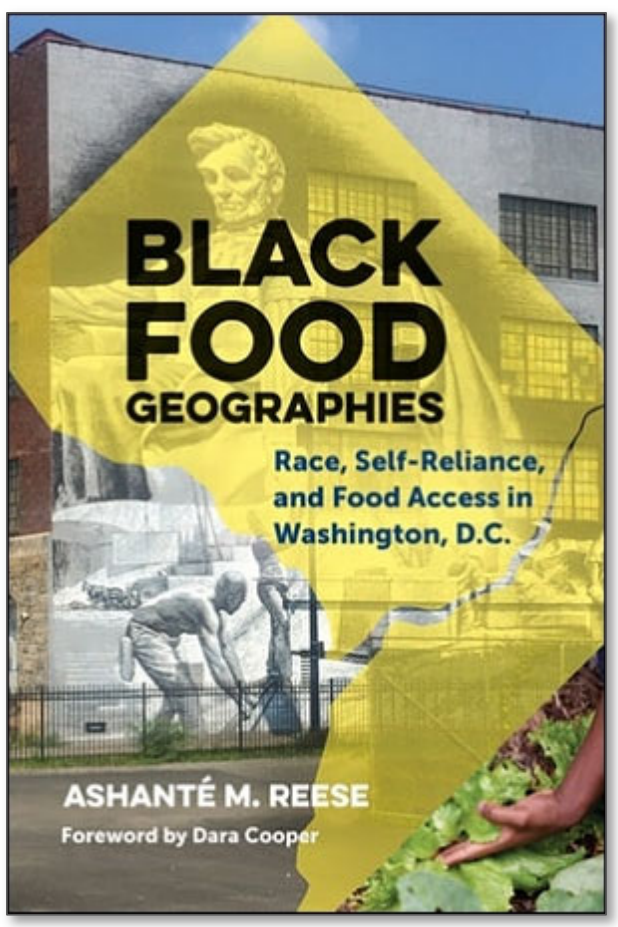

Submitted January 20, 2020 / Published online May 4, 2020

Citation: Catacalos, R. B. (2020). Black residents navigate an unequal food landscape in Washington, D.C. [Book review]. Journal of Agriculture, Food Systems, and Community Development, 9(3), 327-329. https://doi.org/10.5304/jafscd.2020.093.011

Copyright (C) 2020 by the Author. Published by the Lyson Center for Civic Agriculture and Food Systems. Open access under CC-BY license.

$\mathrm{I}^{\mathrm{n}}$ n Black Food Geographies: Race, Self-Reliance, and Food Access in Washington, D.C., Dr. Ashanté Reese guides us through the interconnected issues that affect the food landscape in many low-income Black communities, through the words and experiences of residents of Washington, DC's, Dean-

\footnotetext{
* Renee Brooks Catacalos works for Sustainable Agriculture and Food Systems Funders, a national nonprofit that amplifies the impact of philanthropic investments in support of just and sustainable food and agriculture systems. She is the author of the book The Chesapeake Table: Your Guide to Eating Local, and has been a food system writer and advocate in the midAtlantic region for 15 years. Catacalos is the former publisher and editor of Edible Chesapeake magazine, has served on the staff or board of several local food and sustainable agriculture nonprofits, and is a current member of the steering team for the Chesapeake Foodshed Network. She can be contacted at reneecatacalos@gmail.com.
}

wood neighborhood. In examining residents' "geographies of self-reliance," she uses the neighborhood as a prism to refract the intertwining and contradictory forces hidden within the inaccurate label "food desert." As she says in her concluding chapter, "The neighborhood functions as an intermediary space where macro-level processes, such as where resources are placed, can be connected to micro-level processes, such as how residents determine what to buy and where to buy it from" (p. 131).

In the Introduction, "Black Food, Black Space, Black Agency,” Dr. Reese examines how decades of intentional anti-Black policies intersected with the development of the term "food desert" and argues that "food apartheid" may be the more accurate way to describe neighborhoods like Dean- 
wood. She also shares her methodology and gives some background on her own path to this work as a Black feminist anthropologist. Her liberal interspersion of verbatim interviews centers the experiences of individuals in Deanwood and, importantly, highlights the different ways Deanwood residents of varying ages, economic resources, and perceived social status both reflect on and respond to the challenge of getting the food they need and want.

Chapter 1, "Come to Think of It, We Were Pretty Self-Sufficient: Race, Segregation, and Food Access in Historical Context," orients the reader to the Deanwood neighborhood's history, both as a specific historically Black community within the nation's capital and as a stand-in for the thousands of low-income, mostly minority communities whose food resources slowly disappeared as the food system consolidated in the $20^{\text {th }}$ century. Deanwood is located in the quarter of the city that is east of the Anacostia River. Its relative isolation drew Black families after the Civil War, who built a self-reliant community that once included small grocers and other food retailers. Eventually, the physical and symbolic separation from the rest of the city also separated Black residents from many of the city's economic opportunities, including access to options for grocery shopping.

Chapter 2, "There Ain't Nothing in Deanwood: Navigating Nothingness and the UnSafeway," describes the city's "unequal food landscape" based on race and income. Dr. Reese then reveals the heterogeneity of Deanwood residents, the disparities in their personal resources, and the created infrastructure of community resources that underlie the demographic data through her interviews about shopping at the Safeway that is nearest to their neighborhood or finding other alternatives further afield.

Chapter 3, "What Is Our Culture? I Don't Even Know: Nostalgia and Memory in Evaluations of Food Access," dives into the memories Deanwood residents hold and share about grocery stores and food shopping in the past. While noting that nostalgic memories often come from people remembering "the good or best parts of their past experience" and contrasting that with the worst of their contemporary experience, Dr. Reese con- cludes that "... imagined pasts provide important data for understanding the social change people would like to see or aspects of community life that they believe no longer exist" (p. 90).

As a long-time participant in conversations about local and regional food systems, I found Chapter 4, "He's Had That Store For Years: The Historical and Symbolic Value of Community Market," especially intriguing. In their interviews, residents all spoke with pride and respect about Community Market, a second-generation Black family-owned corner grocery store. Yet they all admitted that they rarely patronized the store because it does not actually meet their shopping needs. This clash between a romanticized version of the way things used to be and the reality of actual consumer behavior is a recurring theme in efforts to relocalize food systems. Dr. Reese's look at the structural forces at play is particularly valuable: "In the larger scope of capitalism, Blackowned businesses like [Community Market] are examples of why class analysis without racial analysis is incomplete" (p. 105).

The interplay between structural and placebased efforts to address the gaps and inequities in the food system are further explored in Chapter 5, "We Will Not Perish, We Will Flourish: Community Gardening, Self-Reliance, and Refusal." Residents seeking to build self-reliance, especially for youth, through a community garden at a public housing complex found that "the garden itself did not radically redistribute wealth, decrease reliance on supermarkets, or . . . bring any noteworthy attention to how the residents were trying to help themselves" (p. 129). The garden, however, did provide a community rallying point through which they were able to illuminate underlying structural gaps in economic and social opportunities available to Deanwood residents.

In her conclusion, "Black Lives and Black Food Futures,” Dr. Reese points out in various ways that "food is never just about food." She goes on to say that "self-reliance as a strategy is best realized through concerted, collective action that addresses multiple needs" (p. 138). She touches briefly on current efforts to organize a food co-op in Ward 7, the food sovereignty work of the National Black Food and Justice Alliance, and the 
racial justice work of the Movement for Black Lives, all of which are ways of looking at how the Black "self" is experienced in relation to community and the seeds of the food future hoped for by residents of Deanwood and beyond. I also appreciated her powerful personal reflections on identity and engaged anthropology in food studies.

Black Food Geographies demonstrates how systemic food inequity shapes the daily experience of people living in a neighborhood with low food access. While the book does not necessarily offer solutions, it does tell us quite explicitly that communities are not passively waiting for outside help, even though they recognize that outside change will also be needed in addition to their communitybased efforts. Dr. Reese also reminds us that numbers do not tell the story. People do that, and we can learn a lot when we listen. 